\title{
CFC/Cu Bond Damage in Actively Cooled Plasma Facing Components
}

\author{
J. Schlosser ${ }^{\mathrm{a}}$, E. Martin ${ }^{\mathrm{b}}$, C. Henninger ${ }^{\mathrm{c}}$, J. Boscary ${ }^{\mathrm{d}}$, G. Camus ${ }^{\mathrm{b}}$, F. Escourbiac ${ }^{\mathrm{a}}$, D. Leguillon ${ }^{\mathrm{c}}$, \\ M. Missirlian ${ }^{\mathrm{a}}$, R. Mitteau ${ }^{\mathrm{a}}$ \\ ${ }^{a}$ Association Euratom-CEA, CEA/DSM/DRFC, CEA Cadarache, F-13108 Saint Paul Lez Durance, France \\ ${ }^{\mathrm{b}}$ LCTS, CNRS UMR 5801, Université Bordeaux 1, Pessac, France \\ ${ }^{\mathrm{C}} \mathrm{LMM}$, CNRS UMR 7607, Université P. et M. Curie, Paris, France \\ ${ }^{\mathrm{d}}$ IPP-Euratom Association, Garching, Germany
}

Pacs : 52.40.Hf; 81.05.Uw

\begin{abstract}
Carbon fibre composite (CFC) armours have been successfully used for actively cooled plasma facing components (PFCs) of the Tore Supra (TS) tokamak. They were also selected for the divertor of the stellarator W7-X under construction and for the vertical target of the ITER divertor.

In TS and W7-X a flat tile design for heat fluxes of $10 \mathrm{MW} / \mathrm{m}^{2}$ has been chosen. To predict the lifetime of such PFCs, it is necessary to analyse the damage mechanisms and to model the damage propagation when the component is exposed to thermal cycling loads. Work has been performed to identify a constitutive law for the CFC and parameters to model crack propagation from the edge singularity. The aim is to predict damage rates and to propose geometric or material improvements to increase the strength and the lifetime of the interfacial bond.
\end{abstract}

For ITER a tube-in-tile concept (monoblock), designed to sustain heat fluxes up to $20 \mathrm{MW} / \mathrm{m}^{2}$, has been developed. The optimisation of the CFC/Cu bond, proposed for flat tiles, could be adopted for the monoblock concept.

\section{Introduction}

Tore Supra team has a large experience in the fabrication of water-cooled high heat flux (HHF) components for the fusion Tokamak [1]. After two generations of brazed carbon tiles onto a metallic heat sink, a new bond was developed between CFC tiles and copper by using an active metal casting (AMC®) technique [2]. Developed by Plansee company (Austria), this process allowed the manufacture 
and the installation of a complete toroidal pump limiter (TPL) in the Tore Supra machine, composed of more than 12000 CFC tiles, and hence remarkable plasma performances [3]. This technique is now applied for the fabrication of HHF elements for the W7-X stellarator [4] and foreseen for the future ITER fusion machine [5].

However reception tests and HHF fatigue tests of TPL prototype or series elements showed possible damage of the tile bond [6]. Hence studies were launched in order to better understand the manufacture residual stresses and to model the mechanisms of the tile bond degradation.

\section{Rejection rate of elements at the reception tests for the Tore Supra TPL}

The concept of the TPL elements and their process of fabrication were described extensively [1][6]. Soft copper is first cast onto the laser-structured tile surface to be bonded, in order to form a $\mathrm{CFC} / \mathrm{Cu}$ assembly; then this assembly is electron beam welded on to a CuCrZr heat sink, in which water channels are drilled. The elementary component is armoured with 20 flat tiles (each about $23 \times 22 \mathrm{~mm}^{2}$ and $6 \mathrm{~mm}$ thick), plus a cylindrical shaped tile at one end allowing a leading edge to be formed. The element is $495 \mathrm{~mm}$ long (Fig. 1). A little amount of tiles (1 to 3\%) was found faulty at the end of fabrication and it increased up to 8\% with the use of a new batch of CFC material (N11-98). The crack appears generally in the CFC just above the structured interface and could be detected both by infrared [8] and visual inspection. It is suggested that this mode 1 crack (opening) occurs due to residual stresses at the bond.

\section{Degradation of the tile performance during HHF fatigue tests}

The TPL elements were qualified at the stage of prototypes by high heat flux tests in the FE200 facility: two elements were fatigue tested under a cycling heat load of $10 \mathrm{MW} / \mathrm{m}^{2}$ up to 4500 cycles [9]. These tests were also done on series elements (Fig. 2): the test was interrupted after about 4000 cycles due to faulty tiles [10]. In Fig. 3 (cycling of series element S25) one can see that at the beginning of the cycling test the surface temperature of the tiles are in a wide range of $820-1020^{\circ} \mathrm{C}$, which is attributed to resistive interfaces in some tile bonds. The tile temperature evolution can be compared with those of 
prototypes for which the data of two tiles are plotted in the figure 3 (tile T6 and T10 of element PL2.4). It has to be noticed that the «hot» tiles have a tendency to evolve during cycling. However on the prototypes the tiles did not fail whereas the tile T8 of S25 failed after 1800 cycles and tile T9 after 3800 cycles (due to a sweeping by zone, tests were interrupted when one tile was faulty). The fracture mode is a partial opening of the bond at the $\mathrm{CFC} / \mathrm{Cu}$ interface visible at the tile edge. With the help of a thermographic analysis, a tentative representation of the crack area versus fatigue heat loading was done during HHF tests on prototypes (Fig. 4). For W7-X HHF component prototypes defects were observed as well already at the beginning of the fatigue cycling [7].

\section{Characterisation of the CFC material}

The N11 material was used for Tore Supra whereas NB31 material is used for W7-X and retained for ITER. Both materials are fabricated by SPS (Bordeaux, France) and made from carbon fibres with a carbon matrix. N11 is a Novoltex ${ }^{\circledR}$ material: PAN fibres are weaved and then "needled" in the third direction to do a 3D preform which is then carbonised, CVI densified and graphitized [11]; this material is balanced (warp and weft directions are equivalent) and orthotropic ( $\mathrm{Z}$ direction is weaker). NB31 is made of “ex-pitch” fibres (warp direction) and ex-PAN fibres (weft direction) and produced applying an additional liquid impregnation. Tables 1 and 2 provide the main properties of these materials (in the axes they are used), which keep a good behaviour at high temperature.

These CFCs exhibit a damageable behaviour resulting from the regularly distributed micro-cracks that develop inside the material under loading. The constitutive law for such materials is based on a macroscopic approach with scalar damage variables since micro cracking does not affect the initial orthotropy of the material [12]. As N11 and NB31 are only available in small sized blocks, it is rather difficult to machine adequate samples for tensile, compression and shear tests. Therefore it was proposed to develop first a complete model on a similar high strength Novoltex CFC material available in large plates (as shown in Fig. 5) and then to extrapolate to N11 or NB31 with the help of T or S shaped samples (Fig. 6). 


\section{Residual stresses}

For the flat tile design the calculated residual stresses are very high at the singularity (CFC/Cu interface) on the edge of the tile. In Fig. 7, a very localised tensile stress is visible near the tile edge and increases the risk of damage initiation within the composite (stress free temperature is taken at $450^{\circ} \mathrm{C}$ ). In case of NB31 monoblock design the residual stresses are even more severe increasing the risk of cracks. The calculation shows important plastic deformation around $2 \%$ in the copper layer and high $\sigma_{x x}$ and $\sigma_{x y}$ stresses compared with the tensile strengths (Fig. 8). One can assume a possible crack initiation due to residual stresses and crack propagation under cycling during operation, which induces a lower stress range.

\section{Crack initiation and propagation}

Two modes of fracture of the CFC/Cu bond were described in [6][9][13]. Observations performed on cycled components reveal de-cohesion (mode I) or shear fracture (mode II).

The stress concentration at the edge of the $\mathrm{CFC} / \mathrm{Cu}$ interface can be written in $(r, \theta)$ coordinates as $\sigma_{i j}(r, \theta)=k \cdot r^{\delta-1} \cdot s_{i j}(\theta)+\ldots$ The generalized intensity factor $k$ depends on the loading and on the global geometry, the exponent $\delta$ depends only on the local geometry (i.e. the angles made by the two materials) and $s_{i j}(\theta)$ is a shape factor. A fracture criterion, which combines a strength and a toughness condition [14], enables to predict the initiation of interfacial failure with the condition $k=\left(G^{c} / A\right)^{1-\delta} \cdot\left(\sigma^{c}-\sigma^{i n t}\right)^{2 \delta-1}$ where $\sigma^{c}$ is the interfacial tensile strength and $G^{c}$ the interfacial toughness, $A$ is a geometrical parameter and $\sigma^{\text {int }}$ depends on the residual stress and the plastic strain. This asymptotic approach shows that interfacial cracking can be initiated by residual stresses if the interfacial properties are too poor.

Numerical simulations were also performed to analyse the initiation and the propagation of the interface failure using the Alfano-Crisfield cohesive zone model (CZM) [15] [16]. This bonddamaging model (cf. Fig. 9) uses three parameters: $\sigma^{c}$ the tensile strength of the bond, $\mathrm{G}_{\mathrm{I}}{ }^{\mathrm{c}}$ and $\mathrm{G}_{\mathrm{II}}{ }^{\mathrm{c}}$ the toughness of the bond in mode 1 (opening) and 2 (shear). Using a set of parameters $\left(\sigma^{\mathrm{c}}=60 \mathrm{MPa}\right.$, $\mathrm{G}_{\mathrm{I}}{ }^{\mathrm{c}}=\mathrm{G}_{\mathrm{II}}{ }^{\mathrm{c}}=100 \mathrm{~J} \cdot \mathrm{m}^{-2}$ ) the calculations have shown crack propagation under heat load of $10 \mathrm{MW} / \mathrm{m}^{2}$ 
(Fig. 10). For those parameters damage is governed by the low value of $\mathrm{G}^{\mathrm{c}}$. That emphasizes the need for bond characterisation, which was investigated in [13] and still is a matter of ongoing research [17]. Using previous tensile and shear bond test results [6][13] to identify the parameters, the following set of parameters was identified at room temperature: $\sigma^{\mathrm{c}}=43 \mathrm{MPa}, \mathrm{G}_{\mathrm{I}}^{\mathrm{c}}=1900 \mathrm{~J} \cdot \mathrm{m}^{-2}$, $\mathrm{G}_{\mathrm{II}}{ }^{\mathrm{c}}=3000 \mathrm{~J} \cdot \mathrm{m}^{-2}$. In this case one can suppose that the bond damage is governed by the low value of $\sigma^{\mathrm{c}}$. Characterisation in [13] shows clearly very scattered results, which can explain various tile bond qualities as depicted in Fig. 4.

\section{Possible improvements and conclusion}

At this level of the study various kinds of improvements can be suggested. The first one is to change the local geometry of the $\mathrm{CFC} / \mathrm{Cu}$ bond, for example a filler at the edge leading to a CFC/Cu angle of 120 or $135^{\circ}$ (gain of about $50 \%$ on $k$ [13]). This can be done on flat tiles but also on the longitudinal edges of the monoblocks. The second one is to change the global geometry when it is possible; for example the change of the monoblock tile in a $\mathrm{U}$ shaped tile with a $\mathrm{U}$ shaped $\mathrm{Cu}$ compliant layer leads to a decrease of the residual stresses, as it is shown on Fig. 11 (however still insufficient). The third one is to change the CFC to a more adequate one (compliant to the thermal expansion) and/or the strength ( $\sigma^{c}$, $\mathrm{G}_{\mathrm{I}}^{\mathrm{c}}, \mathrm{G}_{\mathrm{II}}^{\mathrm{c}}$ ) of the bond (change in the laser structuring, carbide formation etc...).

To study the bond damaging of a CFC tile or monoblock the constitutive behaviour law for the CFC and strength parameters of the bond are needed. A lot of tests are still necessary to achieve this task. Nevertheless it has been shown that the bond damage can be calculated using a CZM model. That opens the way to an optimisation of the design concepts (local and global geometry, materials properties...).

\section{Acknowledgement}

This work, supported by the European Communities under the contract of Association between EURATOM and CEA, was carried out within the framework of the European Fusion Development Agreement. The views and opinions expressed herein do not necessarily reflect those of the European Commission. 


\section{REFERENCES}

[1] Schlosser J, Durocher A, Chappuis P, Huber T, Schedler B, Garin P and Agarici G 2001 Fus. Eng. and Des. 56-57 309

[2] Huber T, Plöchl L, Reheis N, Cocat JP and Schlosser J The manufacturing and testing of the toroidal pumped limiter prototype elements for Tore Supra, Proc. 16th IEEE/NPSS/SOFE, Champaign, 1995, pp 716-719.

[3] Mitteau R and Tore Supra team 2005 J. Nucl. Mat. 337-339 795

[4] Boscary J, Böswirth B, Greuner H, Missirlian M, Schedler B, Scheiber K, Schlosser J and Streibl B, Results of the examinations of the W7-X pre-series target elements, Fus. Eng. and Design in press

[5] Merola M, Palmer J and The EU ITER Participing Team 2006 Fus. Eng. and Des. 81105

[6] Schlosser J, Chappuis P, Durocher A, Moncel L and Garin P 2001 Physica Scripta T91 94.

[7] Greuner H, Boeswirth B, McNeely P, and Boscary J High heat flux facility GLADIS Operational characteristics and results of W7-X pre-Series target tests - Nucl Fus. in press

[8] Durocher A et al Interface quality control by infrared thermography measurement, Proc. of the $15^{\text {th }}$ World Conf. on Non-D. Testing, Roma (Italy), Oct. 15-21, 2000.

[9] Moncel L, Schlosser J, Mitteau R and Plöchl L, Active Metal casting technique in Plasma facing Components: characterization, Proc. 20th Symp. on Fusion Technology (SOFT), Marseille, France, Sept. 7-11, 1998, p. 133.

[10] Schlosser J, Escourbiac F, Cordier JJ, Mitteau R, Durocher A and Grosman A, High heat flux testing impact on the Tore Supra toroidal pumped limiter achievement, 20th IEEE/NPSS Symposium on Fusion Engineering (SOFE), San Diego, 2003, p. 92.

[11] Goyheneche JM, Vignoles G and Coindreau O Modélisation thermique des composites thermostructuraux, Proc. of Congrès français de Therm., SFT, Giens (France), May 25-28, 2004, p 19.

[12] Pailhès J, Camus G and Lamon J 2002 Mecha. of Mater. 34161.

[13] Moncel L, Etude des Mécanismes d'endommagement d'un assemblage Cuivre composite Carbone-Carbone, PHD thesis $n^{\circ} 2081$, Bordeaux-1 Univ.

[14] Leguillon D 2002 Eur. J. of Mechanics - A/Solids, 2161.

[15] Alfano G and Crisfield MA 2001 Int. J. Num. Meth. Eng. 501701

[16] Martin E, Schlosser J, Marceau T, Leguillon D and Henninger C Modélisation de l'endommagement de l'interface Composite /Cuivre au sein des composants à hauts flux pour la Fusion Contrôlée, Proc. Matériaux 2006, Dijon (France), Nov. 13-17,

[17] Schedler B, Huber H, Eidenberger E, Scheu T and Pippan R, Clemens H Methods to determine the joint strength of C/C to copper joints Fus. Eng. and Design in press 


\section{FIGURE CAPTIONS}

Fig. 1: TPL finger manufacturing process

Fig. 2: TPL elements installed in the HHF EB facility chamber

Fig. 3: Surface temperature evolution of the tiles versus fatigue heat cycling at $10 \mathrm{MW} / \mathrm{m}^{2}$ for the element S25 fabricated with the grade N11-92

Fig. 4: Tentative damage representation of CFC-Cu joints versus HHF fatigue cycling for prototype elements

Fig. 5: Typical shear behaviour of a high strength Novoltex CFC material in xy plane

Fig. 6: Typical S and T samples allowing to monitor a complex strain field during a tensile test

Fig. 7: FE calculation of the $\sigma_{\mathrm{yy}}$ stress along the edge of the element (compared with the tensile strength of $50 \mathrm{MPa}$ for N11 in this direction)

Fig. 8: FE calculation of the residual stress field for a NB31 monoblock

Fig. 9: Damage law between 2 face-to-face nodes of the CZM (t, u being force and displacement, $n$ for normal and t for tangential, $\mathrm{G}$ is the triangle area)

Fig. 10: Example of crack propagation calculation under heat load after a few cycles using cohesive zone modelling

Fig. 11: Calculated residual stress field showing decreased stresses due to geometry change 


\section{TABLES}

Table 1: Typical mechanical properties of the used N11 and NB31 CFC (tensile and shear strengths in MPa)

\begin{tabular}{|l|c|c|c|c|c|c|c|}
\hline & $\mathbf{T}$ & Sxx & Syy & Szz & Sxy & Sxz & Syz \\
\hline N11 & $\mathbf{2 0}^{\circ} \mathbf{C}$ & 50 & 50 & 19 & 24 & 18 & 18 \\
\hline N11 & $\mathbf{1 0 0 0}^{\circ} \mathbf{C}$ & 60 & 60 & 28 & & & \\
\hline NB31 & $\mathbf{2 0}^{\circ} \mathbf{C}$ & 30 & 110 & 15 & $9-19$ & 9 & 15 \\
\hline
\end{tabular}

Table 2: Typical thermal properties of the used N11 and NB31 CFC $\left(\lambda: \mathrm{W} \cdot \mathrm{m}^{-1} \mathrm{~K}^{-1} ; \mathrm{Cp}: \mathrm{J}^{\mathrm{kg}}{ }^{-1} \mathrm{~K}^{-1} ; \rho: \mathrm{kg} \cdot \mathrm{m}^{-3}\right)$

\begin{tabular}{|l|c|c|c|c|c|c|}
\hline & $\mathbf{T}$ & $\lambda x x$ & $\lambda y y$ & $\lambda z z$ & Cp & $\rho$ \\
\hline N11 & $\mathbf{2 0}^{\circ} \mathbf{C}$ & 220 & 220 & 166 & 670 & 1950 \\
\hline N11 & $\mathbf{1 0 0 0}^{\circ} \mathbf{C}$ & 90 & 90 & 70 & 1750 & 1920 \\
\hline NB31 & $\mathbf{2 0}^{\circ} \mathbf{C}$ & 100 & 250 & 80 & 780 & 1900 \\
\hline NB31 & $\mathbf{8 0 0}^{\circ} \mathbf{C}$ & 50 & 125 & 40 & 1820 & \\
\hline
\end{tabular}

\section{FIGURES}

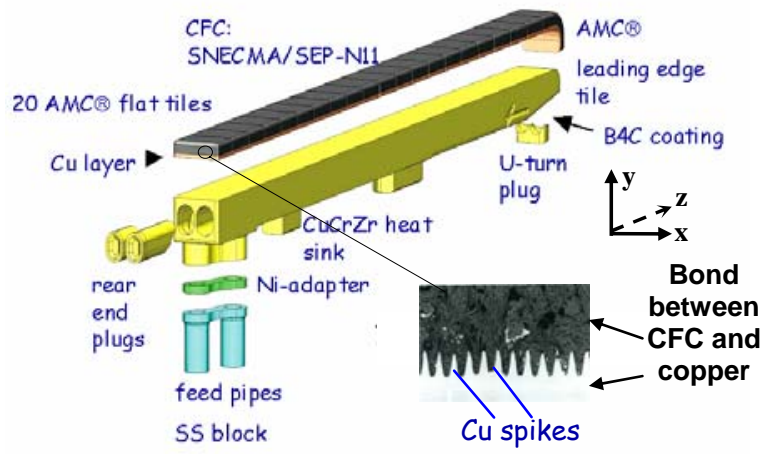

Fig. 1: TPL finger manufacturing process

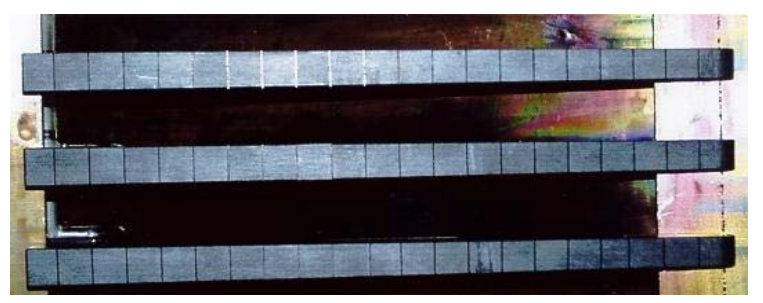

Fig. 2: TPL elements installed in the HHF EB facility chamber

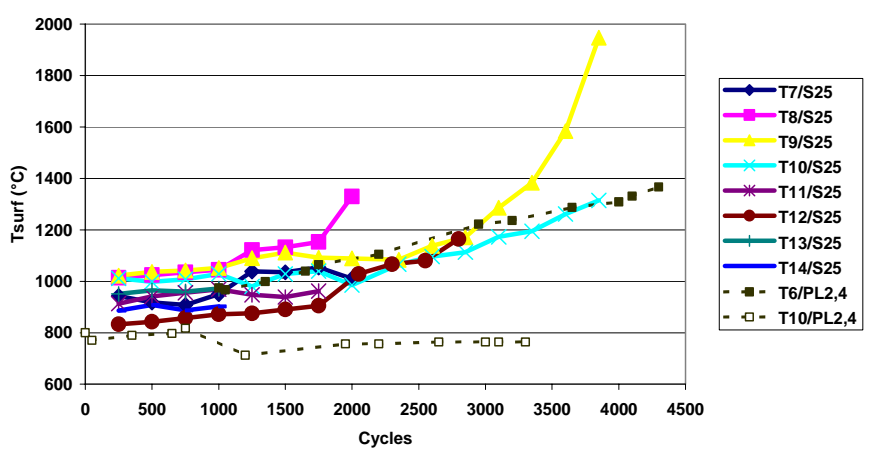

Fig. 3: Surface temperature evolution of the tiles versus fatigue heat cycling at $10 \mathrm{MW} / \mathrm{m}^{2}$ for the element $\mathrm{S} 25$ fabricated with the grade N11-92

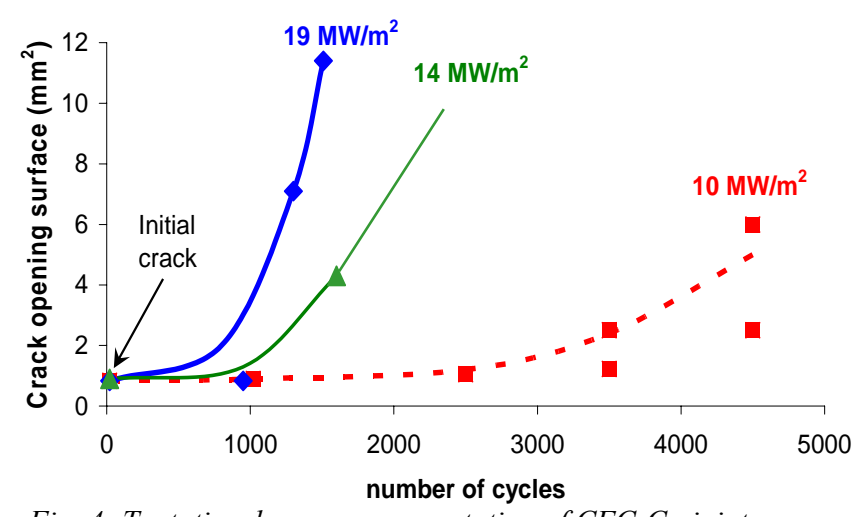

Fig. 4: Tentative damage representation of $C F C$-Cu joints versus HHF fatigue cycling for prototype elements 


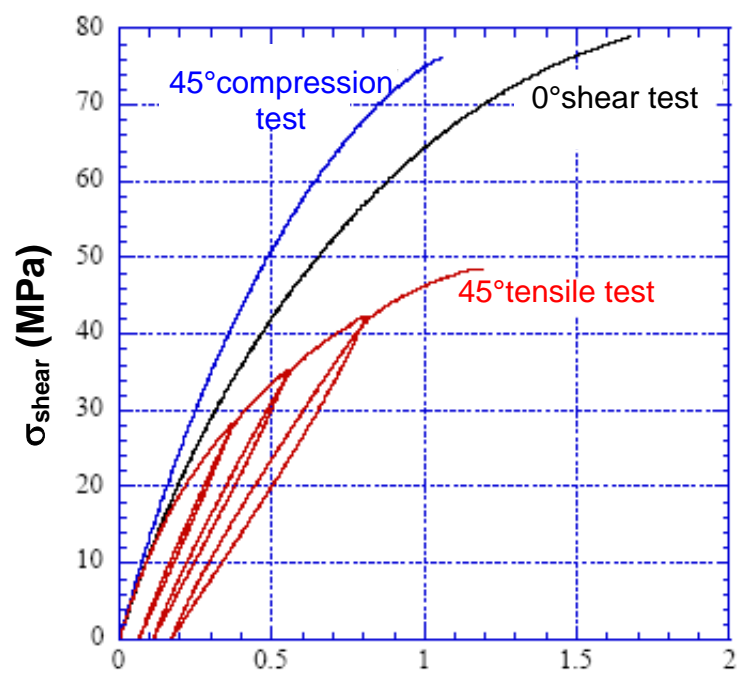

Fig. 5: Typical shear behaviour of a high strength Novoltex CFC material in xy plane
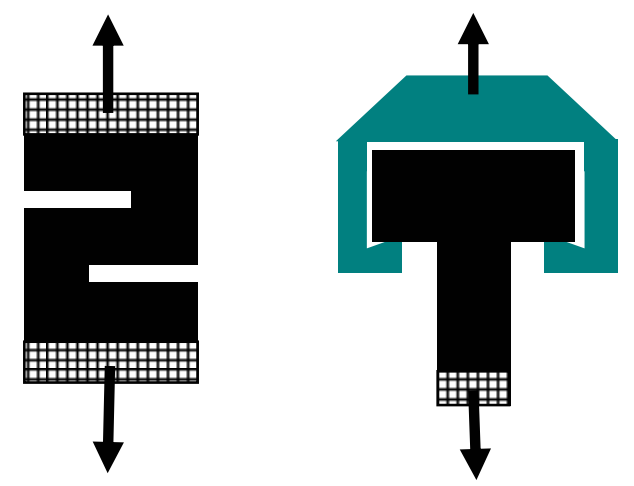

Fig. 6: Typical $S$ and $T$ samples allowing to monitor a complex strain field during a tensile test

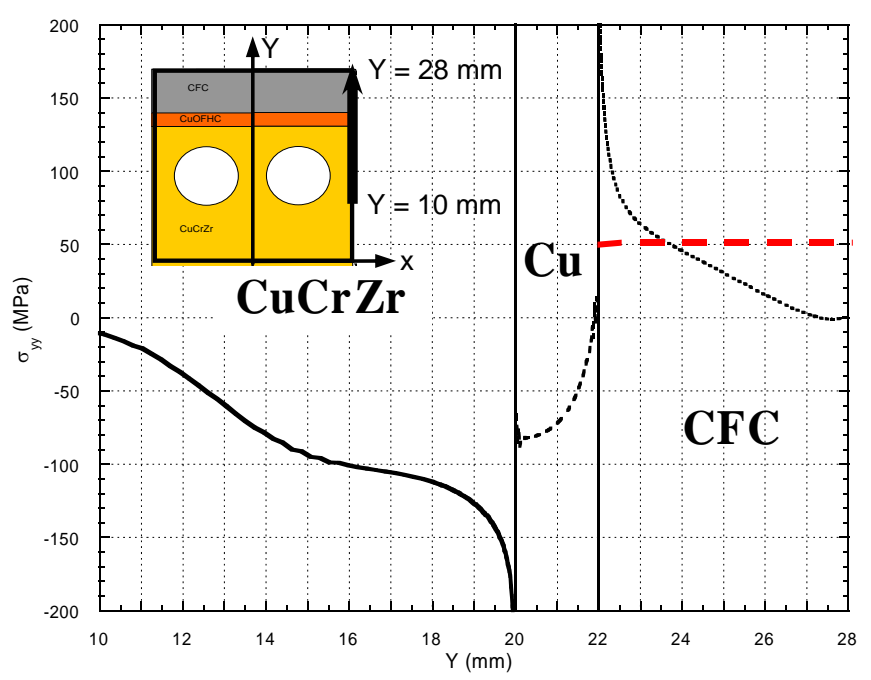

Fig. 7: FE calculation of the $\sigma_{y y}$ stress along the edge of the element (compared with the tensile strength of $50 \mathrm{MPa}$ for N11 in this direction)

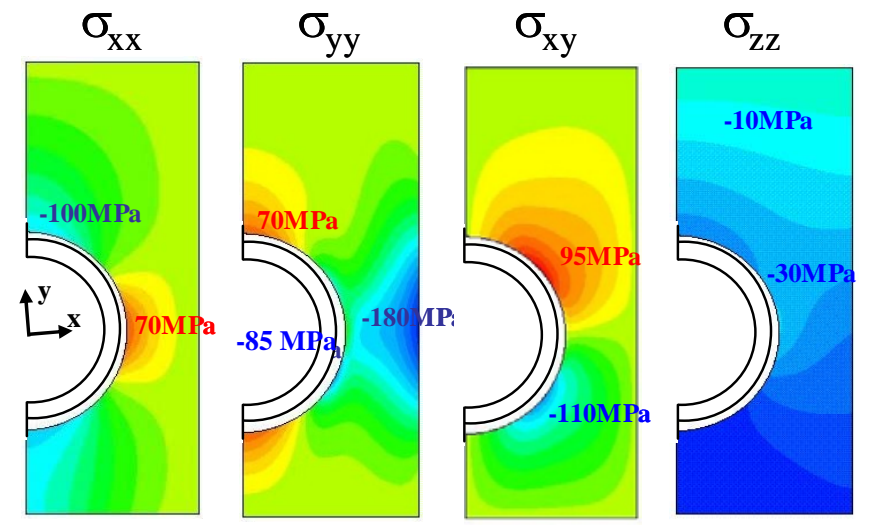

Fig. 8: FE calculation of the residual stress field for a NB31 monoblock
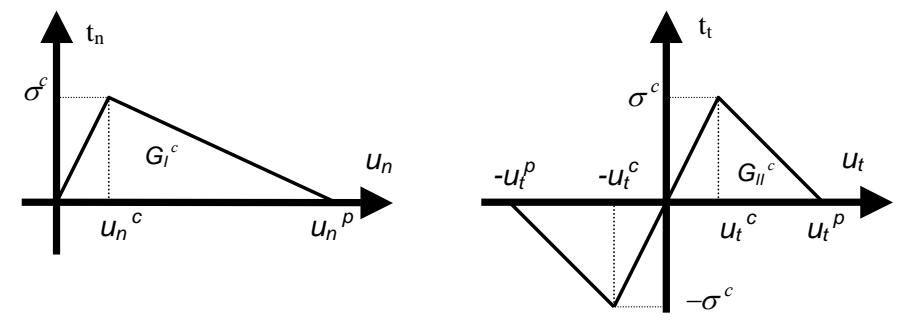

Fig. 9: Damage law between 2 face-to-face nodes of the CZM ( $t, u$ being force and displacement, $n$ for normal and t for tangential, $G$ is the triangle area)

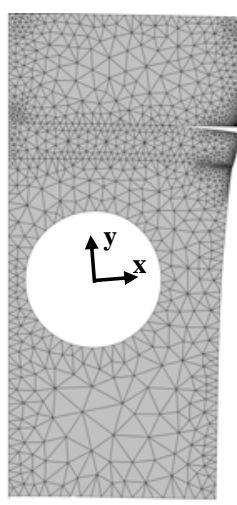

Fig. 10: Example of crack propagation calculation under heat load after a few cycles using cohesive zone modelling

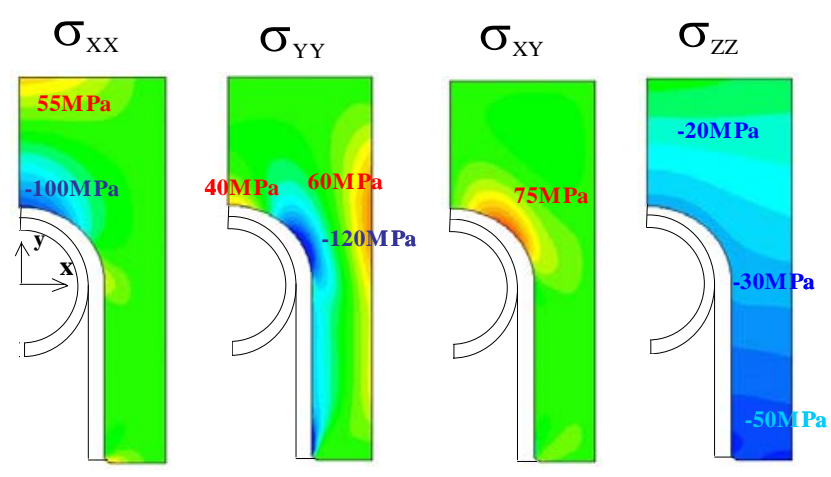

Fig. 11: Calculated residual stress field showing decreased stresses due to geometry change 
